This item was submitted to Loughborough's Research Repository by the author.

Items in Figshare are protected by copyright, with all rights reserved, unless otherwise indicated.

\title{
A fitting problem: Standardising shoe fit standards to reduce related diabetic foot ulcers
}

PLEASE CITE THE PUBLISHED VERSION

https://doi.org/10.1016/j.diabres.2019.05.017

\section{PUBLISHER}

(C) Elsevier

\section{VERSION}

AM (Accepted Manuscript)

\section{PUBLISHER STATEMENT}

This paper was accepted for publication in the journal Diabetes Research and Clinical Practice and the definitive published version is available at https://doi.org/10.1016/j.diabres.2019.05.017.

\section{LICENCE}

CC BY-NC-ND 4.0

\section{REPOSITORY RECORD}

Jones, Petra J., Richard Bibb, Melanie J. Davies, Kamlesh Khunti, Matthew McCarthy, Daniel Fong, and David Webb. 2019. "A Fitting Problem: Standardising Shoe Fit Standards to Reduce Related Diabetic Foot Ulcers". Loughborough University. https://hdl.handle.net/2134/37805. 


\title{
Title: A Fitting Problem: Standardising Shoe Fit Standards to Reduce Related Diabetic Foot Ulcers
}

\author{
Author Names and Affiliations \\ Petra J Jones ${ }^{a}$, Richard J Bibb ${ }^{b}$, Melanie J Davies ${ }^{a}$, Kamlesh Khuntia, Matthew McCarthya ${ }^{a}$, Daniel TP \\ Fong and David Webba \\ a Leicester Diabetes Centre, Leicester General Hospital, Leicester, UK \\ b Loughborough Design School, Loughborough University, Loughborough, UK \\ c School of Sport, Exercise and Health Sciences, Loughborough University, UK \\ Corresponding Author: \\ Phone: \\ Email: \\ Address: \\ Dr Petra J Jones \\ 01162584974 \\ pj100@leicester.ac.uk \\ Origin Ward, Leicester Diabetes Centre, Leicester General Hospital, \\ Gwendolen Road, Leicester, Leicestershire, LE5 4PW
}

\section{Abstract (199 words)}

Aims: Incorrectly fitting shoes are implicated in callus formation and a significant proportion of diabetic foot ulcers, yet remain surprisingly prevalent. We review the current shoe fit guidelines for consistency and discuss ways in which technology may assist us in standardising methods of footwear assessment. Methods: Narrative review.

Results: Incorrectly fitted shoes are implicated the development of some diabetic foot ulcers yet surprisingly there's no consensus on shoe fit, despite substantial spending on prescription footwear. Suggested toe gaps vary from 6-20mm and measurement methods also vary from Brannock Devices and callipers to manual measurement.

Conclusions: To prevent fit-related foot ulceration, we need to standardise our biomechanical definition of fit. Future research should (1) evaluate the potential use of 3D scanning technology to provide a standardised means of capturing foot morphology; (2) develop a working biomechanical definition of fit, including toe gap through the identification of key physiological markers that capture and predict dynamic foot shape changes during different physical activities and body weight loading conditions; and (3) determine whether changes in dynamic foot shape of those with diabetes differs from those without, impacting on their shoe fitting needs, potentially necessitating specialist footwear at an earlier stage to avoid ulceration.

\section{Keywords}

Footwear, biomechanical, fit, guidelines, diabetes, and ulceration 


\section{Introduction}

Fifteen percent of the 3.68 million people in the UK who have been diagnosed with diabetes, [2] are likely to develop a foot ulcer in their lifetime [3]. The cost of their foot care has been estimated at around $£ 580-£ 662$ million, accounting for $0.6-0.7 \%$ of NHS expenditure in England (2010-11) [4]. Those estimated foot care costs are broken down into $£ 55$ million on amputation and post-operative care, $£ 219$ million of inpatient care and $£ 306$ million on primary, community and outpatient care relating to ulceration [5]. Since then those costs will have risen given the increasing prevalence of diabetes [6] with an estimated 4,000 deaths per year due to diabetes foot ulcer (DFU) and subsequent amputation [7]. Despite investment via the Diabetes Transformation Fund [8] which aims to improve access to multi-disciplinary foot care teams, the number of lower limb amputations has still increased [9].

Many older people in the general population wear shoes that are too narrow (46-81\%) [10] or casual footwear that is too loose [11]. In a study by McInnes, the majority of participants were wearing footwear of incorrect length [12]. When comparing those with diabetes $(n=85)$ to those without ( $n=118$ ) $82 \%$ of those with diabetes had a different between foot and shoe length outside the acceptable range as compared with $66 \%$ without diabetes. No significant difference in fit was found in participants with and without neuropathy. The suggestion that incorrectly-fitting shoes may be common among those with diabetes, is also supported by Harrison [13] who found that only $24 \%$ of patients attending a general diabetes clinic $(n=100)$ were wearing shoes of the correct length and width for both feet whilst seated and even less (20\%) whilst standing. Whilst we know footwear remains an important factor in DFU, there is a surprising lack of consensus among healthcare professionals around what constitutes 'incorrectly fitted', 'too narrow' or 'incorrectly sized' shoes, and even around which tools and procedures to use when measuring feet or assessing the fit of footwear. In this paper, we highlight these gaps and suggest some possible approaches.

\section{Methodology}

This narrative review is based on a detailed literature review on this topic that included a Medline search using the following keywords: 'diabet*', 'shoe', 'fit', 'incorrect', 'size', 'ulcer' and 'fitting'.

\section{The Relationship between Shoe Fit and Diabetes Foot Ulcers}

When we review the evidence for a link between incorrectly fitting shoes and DFU, one of the earliest studies was by Reddy, Vaid and Child who found $37.1 \%$ of those with diabetes ( 26 of 70 ) were wearing shoes that we too tight (a length of shoe shorter than one or more British shoe size). They found no increase in callosities related to shoe tightness either in those with diabetes $(n=70)$ or without $(n=50)$ but amongst those with neuropathy as well as diabetes, callosities were present in three out of six patients wearing tight shoes [14]. Macfarlane and Jeffcoate found that in 138 cases (20.6\%) out of 69 the break in skin was definitely caused by rubbing from footwear [1]. This was further broken down into non-specific rubbing, including significant foot deformity (73.2\%), new shoes (5.1\%), work/wellington boots (4.3\%), thick socks (2.2\%), ill-considered exercise (2.9\%), other (2.2\%) and most surprisingly of all, new shoes provided by an orthotist (10.1\%) [1]. In addition, a further 24 ulcers post-surgery (3.6\%) were attributable to professional factors including rubbing from supplied footwear or plaster casts designed to alleviate pressure. Reiber examined the causal chain leading to amputation in 80 patients with diabetes and neuropathy identifying multiple 
pathway components, but suggested in nearly half of patients there was a pivotal event that was footwear-related [15].

Certainly it seems plausible to suggest that a majority of dorsal ulcers results from incorrectly-fitting footwear but many questions about the relationship between fit and foot ulceration remain unanswered. For instance, peak plantar shear stress has recently been found to be higher in patients with a history of DFU representing a risk factor for recurrence [16] but how much additional pressure or shear stress is caused to feet by incorrectly fitted footwear is unclear.

The relationship between incorrectly fitting footwear and in-shoe microclimate, including temperature, pressure, and humidity, of which peak plantar shear stress forms part, requires further research. Until recently research has been hampered by the lack of a standardised approach to the assessment of the combinations of gait and plantar pressure abnormalities [17]. If we are to evaluation the suggestion that wearing correctly fitting shoes (length and width) has the potential to prevent callus formation by reducing pressure and sheer stress under the second and fifth metatarsal heads [18], we must first examine what constitutes good fit, how it is defined and assessed.

\section{If the Shoe Fits: A Lack of Consensus on Length?}

Poorly fitting shoes are a frequent problem among many people, not just those with diabetes. For instance, $59 \%$ of participants with rheumatoid arthritis were found to be wearing shoes of incorrect size [19]. A lack of standardisation in commercial footwear sizing, a range of alternative measurement methodologies and finally, enormous variation in the acceptable range for foot-toshoe gaps have obscured the definition of a good shoe fit (see Table 1). This makes variation in patient foot care highly likely and makes large scale estimates of the prevalence of ill-fitting footwear among people with diabetes more difficult (see Fig.1). Approximately $13 \%$ of all DFUs are located on the dorsum of digits [20]. As this area of the foot is not in direct contact with the ground, ill-fitting shoe fit, especially in the toe box area of the shoe is considered responsible [21].

\section{[TABLE 1 HERE - SEE END OF DOCUMENT]}

\section{[FIG.1 HERE - SEE END OF DOCUMENT]}

Besides the significant variation in foot-to-shoe gap ranges, opinions also differ on whether the measurement of the participant's foot should be seated or standing (weight bearing). Currently, guidance in ISO 7250 [23] states that foot length and width measurements should be taken with the subject in a standing position, with $50 \%$ of their weight on each foot but as Telfer and Woodburn point out, there is a lack of evidence regarding which combination of weight bearing and position during scanning yields the best shoe fit [24]. The Canadian Association of Wound Care also recommended taking measurements whilst the participant is seated and standing [25]. However, the work of Grau and Barisch-Fritz suggest we may need to go further. During their study of 912 industrial workers, they found that most length, width, height and angular measures increased during dynamic loading (rather than the static loading of standing) whereas all circumference measures decreased [26]. Capturing dynamic foot morphology during movement has, until now, been technologically difficult, which is why such methods have yet to be applied to those with diabetes and neuropathy. To summarise, there is a clear need for standardisation in method, equipment used, and in the definition of an acceptable gap range. A study of foot morphology 
during dynamic loading in those with diabetes and neuropathy is needed to enhance our understanding of how foot shape changes within the confines of footwear designed to minimise ulceration. Once we have a standardised working definition of fit, acquired through such a study, we can begin to evaluate pressures and shear forces associated with correctly fitting and incorrectly fitting shoes upon the feet of those with diabetes and neuropathy.

\section{Foot Width, Weight-Bearing and Toe Splay}

We find similar problems when looking at shoe fit in the context of width. Chantelau and Gede [11] found that two thirds of feet in elderly participants $(n=568)$ were considerably broader than the normal footwear available [11]. Tovaruela-Carrión et al. [19] could not find any reference regarding the normal gap of the foot-to-shoe width and therefore chose the medial aspect of the first metatarsal head and the lateral aspect of the fifth metatarsal head ('forefoot transversal line') as the measure of fit [19].

Some gap between the toes and the inside of the shoe is necessary given the need for toe splay whilst walking, standing, or engaged in other weight-bearing activities of variable load [11] but there is some debate here also as to appropriate fit [12] (see Table 2) and considerably less research than on foot length.

\section{[TABLE 2 - SEE END OF DOCUMENT]}

Tsung et al. found that increased weight bearing in normal feet significantly increased the contact area of the foot, both in terms of length and width, including the rear foot width whilst decreasing the average height, arch height and arch angle based on an analysis of the digital shape of sixteen foot casts in non-weight bearing, semi-weight bearing and full-weight bearing conditions [29]. This raises some fundamental issues around our conception of fit: firstly, if the foot dynamically changes dimensions under varying loads and biomechanical pressures, which are the most important measurements to make and under which conditions? Secondly, does the foot shape of those with diabetes and neuropathy dynamically change to the same extent as those whose feet are unaffected by diabetes? Finally, how often should we measure feet? Connolly and Wrobel found $48 \%$ of US veterans ( $n=200$, where $51 \%$ had diabetes, $21 \%$ neuropathy and $7 \%$ previous foot ulcer) showed a full change in shoe size after enlistment, which they attributed to weight change and possible ligamentous laxity (foot splay) [30].

The challenge in clarifying what we mean by fit, of course, is further complicated when dealing with unique characteristics from an amputated toe to hallux valgus and also by variables like temperature [28]. When considered together, our current approach to fitting (or poorly fitting) shoes is highly subjective and lacks rigour or evidence base.

\section{D Scanners: A New Path to Foot Morphology?}

What is needed is a way of measuring feet that takes account of the foot's natural dynamic morphology; meaning its shape not just dimensions and how that shape changes through the normal ranges of movement. One way to do this might be through 3D scanning, which is a process for capturing digital information about the shape of an object using structured light or lasers. This is advantageous as it is non-invasive and safe. There have been many studies that have employed 3D 
scanning in a range of medical applications [31]; with techniques and equipment that are widely recognised [32] and commercially available. Unlike physical measurements, impressions or casts 3D scanning can capture the shape of anatomy (even the softest tissues) without any contact.

For example, Telfer and Woodburn showed that 3D scanning of the foot offers the potential to reduce errors resulting from skin displacement or tissue distortion [33], and the findings of Lee et al. [34] suggest 3D scanners provide higher precision, accuracy and robustness when compared against digital callipers, Harris mats and digital footprint images on six measured foot dimensions ( $n=130$, $\mathrm{P}<0.05$ ) and other studies advocate their use [35]. If we were to use 3D scanners as the basis for individualized footwear designs, challenges include accurate and repeatable scanning protocols, well-defined design parameters and manufacturing tolerances [36]. A preliminary study using a 3D scanner and printer to manufacturer orthoses compared favourably to the traditional plaster-based approach, although only one participant was included [37]. 3D scanning and computer numerical control machining (aka CNC, converting a design into numerical measurements) and increasingly 3D Printing are being use by clinical [38] and commercial orthotics providers. However, these typically only capture the plantar surfaces for the provision of corrective insoles.

The first issue to be resolved is what we should be scanning. 3D scanners have the potential to capture the changing foot shape of a person with diabetes as he or she moves through different weight bearing phases of his or her gait. Stankovic et al. found that $92.6 \%$ of total foot shape variation can be captured using six principal components reflecting arch height, combined ball width and inter-toe distance, global foot width, hallux bone orientation, (see Fig.2 below) midfoot width and foot type [39].

\section{[FIG.2 - SEE END OF DOCUMENT]}

In their method four scans were required: two for each foot, one with full body weight and the other bearing only $50 \%$ of the weight by holding a side wall. One immediate difficulty is that this position had to be held by the participant for approximately fifteen seconds to obtain the scan [39]. A proportion of participant may not be able to do this but fortunately faster techniques have since been developed. It is now possible to capture dynamic foot shape whilst walking or engaged in other physical activity have been devised using six sets of high-speed cameras [40], multiple laser plane triangulation [41] and multi-view stereo using 12 video cameras [42], although it is yet to be specifically applied to the diabetic foot. 3D scanning technology has now made it possible to record foot shape during walking [43]. Barisch-Fritz et al. concluded during a 3D scanner study of children and adolescents' foot deformation during walking that dynamic medial ball length is important to appropriately consider the foot-to-shoe length gap although they did not offer guidance on ranges given that additional information on space for growing and in-shoe movement must be considered to calculate the toe allowance [43]. Calculating an appropriate range for this gap for adults or children with diabetes should be the objective of future research, analysing exactly how much space is needed in three dimensions as the foot deforms and changes shape. We can then begin to develop 3D models of fit informed by practical research.

Even as the foot dynamically changes shape under varying loads and biomechanical pressures, we have seen that we may be able to capture dynamic foot shape variation. We could then develop machine learning algorithms which, given known variables (age, height, weight etc.), might predict dynamic changes in foot shape from only 3D scans of participant's feet in a few poses minimizing the need for stitching elements from multiple scans together and the introduction of associated errors. We might also use 3D scanning technology to begin to clarify what constitutes a good fit through 
practical research in the area of foot-to-shoe length gap and the proportion of such a gap necessary for movement with minimal friction and sheer pressures.

But what of the other question we posed: does the foot shape of those with diabetes dynamically change to the same extent as those whose feet are unaffected by diabetes? Here too, there is a need for more research. Rao et al. found both reduced segmental foot mobility in individuals with diabetes as well as reduced foot splay [44], which implies a decreased total surface area over which to distribute body weight across the foot with the pressure spread across a smaller area. How does fluctuation in foot shape during physical activity differ in healthy adults from those with diabetes? How does this impact on gait, physical activity, peak sheer pressure, temperature and friction and finally how does it affect our definition of shoe fit?

\section{After scanning: footwear design and biomechanics testing}

If we are able to successfully capture foot shape through 3D scanning, the next step in the manufacture of custom fitting-footwear is to make the shoe "last", which is the approximate shape of the human foot. The last forms a reference object onto which shoes are designed. ComputerAided Design (CAD) has been widely employed in the footwear industry for making customised shoes [45]. Shoes are three-dimensional (3D) objects and in CAD the design is drawn in a virtual 3D environment. By digitally comparing the shape of the last and the foot, fit can be quantified by the distance between the nearest coordinates on the last and on the foot.

However, this is only a static comparison. Shoes are for movements and therefore dynamic tests should be done; typically called biomechanics tests. When a person performs movements, such as walking, running, jumping, etc., there will be movement within the foot segment as the human foot is not a single rigid body segment [46, 47]. The most obvious motion happens at the metatarsal joints, through bending of the toes, in order to land on the ground and push off from the ground. Therefore, during these movements, the previous measurement of fit during the static condition will not be valid. Cheng and Hong [48] developed a method to quantify the fit of running shoes. In addition to the dimensional difference between the shoe last and the foot shape obtained by 3D scanning, they measured the pressure at 12 selected locations on the dorsal foot by individual flexible sensors. They performed regression analysis and were successful in quantifying overall fit by the dimensional difference and/or pressure sensor data.

Another important parameter related to fit is the plantar pressure distribution. For shoes to be comfortable, it is better to distribute body weight as evenly as possible over the whole plantar area. This is called the 'foot-bed' concept: a bed is comfortable if it deforms to fit the body contour and therefore avoid localised high pressures [49]. This plantar pressure distribution can be measured easily with pressure sensitive insoles that have a full coverage of the plantar area [50]. It can be used in dynamic situations so peak pressure points can be revealed during the gait cycle in walking, running or other movements.

Finally, Finite Element Modelling (or Finite Element Analysis) [51] has been introduced to evaluate the plantar pressure in a systematic way with lowered cost. The shapes of the foot and the shoe soles are scanned and input to a virtual computer environment. The surfaces of these objects are transformed into mesh with finite number of 'elements', and the analysis can calculate the pressure acting on each of these elements. This can be done in static and dynamic, or quasi-static conditions [52]. With the use of this method, the designer can adjust the design of the shoe soles or material at local locations in order to evenly distribute the pressure for the best comfort, and this has also been applied on therapeutic footwear [53] and diabetic footwear recently [54]. 


\section{Conclusions}

It is clear from the literature that in clinical applications there is a lack of consensus about what constitutes an ill-fitting shoe both in terms of the common measures of foot-to-shoe length and width or on the methods used to make these measurements. Despite the strongly suspected relationship between poor fit and a substantial proportion of diabetic foot ulceration, shoe fitting currently remains an art and not a science. We propose a study using a 3D scanner coupled with cameras to capture dynamic changes in foot shape to collect invaluable data for refining our rough definition of biomechanical fit. Although costs are falling significantly, 3D scanners remain expensive in comparison to simple devices like calipers. However, DFU constitutes the primary cause of hospitalisation in people with diabetes [55], and given the costs to the NHS between $£ 972$ million $£ 1.13$ billion per year in England alone [56] this the potential of this technology to reduce costs should be explored. If it can be demonstrated that a good fit can be defined more accurately and easily than existing techniques these costs might be offset by quantifiable cost savings in terms of increased uptake of prescription shoes and adherence in wearing them, reduced wastage and decreases in DFU and the costs associated with complications.

More research is required to predict changes in dynamic foot measurement under various weight loading conditions during physical activity, which 3D scanners have only recently evolved to be able to capture. It would then be possible to develop computer models that predict changes in shape from scan data acquired during only one or two positions, and ascertain which measurements are most crucial and in what proportion in their contribution to a biomechanically good shoe fit, including perhaps a more precise foot-to-shoe length and width. Of course, there are many other qualitative aspects to fit that need to be considered including comfort, ergonomics and material qualities and aesthetics but these are all underpinned by the fundamental quantitative aspects of fit essential to efficient economy of movement.

The speed and sophistication of 3D scanners continues to improve and we now have the potential to carry out additional research to further our understanding of dynamic foot shape variation in those with and without diabetes, how they may differ and whether that extends beyond reduced foot splay into other aspects of dynamic foot shape and how this contributes both to effective footwear pre-requisites and peak plantar sheer stress and pressures around the second and fifth metatarsal heads and broader forefoot area. The effect improved fit might have on proprioception should also be explored.

Finally, foot shape and properties such as ligamentous laxity change over time raising the issue of how regularly feet should be measured in both people with or without diabetes - certainly regular reviews are indicated. 3D scanners provide us with a rapid means of capturing the morphology of feet and in so doing, enable us to begin to develop the science of shoe fitting to facilitate customized footwear solutions tailored to the need of the individual with diabetes.

\section{Funding sources}

None.

\section{Competing interests}

None declared. 


\section{References}

1 Macfarlane RM, Jeffcoate WJ. Factors contributing to the presentation of diabetic foot ulcers. Diabet Med 1997; 14: 867-70. https://doi.org/10.1002/(SICI)1096-9136(199710)14:10\%3C867::AID-DIA475\%3E3.0.CO;2-L. Diabetes UK. Diabetes prevalence 2017 (November 2017). [accessed 07 May 2019] Available from: https://www.diabetes.org.uk/professionals/position-statementsreports/statistics/diabetes-prevalence-2017

3 Reiber Ge. The epidemiology of diabetic foot problems. Diabet Med 1996; 13(Supp 1): S611.

4 Kerr M, Rayman G, Jeffcoate WJ. Cost of diabetic foot disease to the National Health Service in England. Diabet Med 2014; 31: 1498-1504. https://doi.org/10.1111/dme.12545NHS. Diabetes, Foot Care for People with Diabetes in the NHS in England: The Economic Case for Change (2012) Factsheet No 37, [accessed 07 May 2019] Available from: https://diabetesresources-production.s3-eu-west-1.amazonaws.com/diabetes-storage/201708/Factsheet\%20Footcare.pdf

5 Above, Kerr et al, Table 3, 1502.

6 Diabetes UK. Number of people living with diabetes doubles in twenty years. 27 February 2018. [accessed 07 May 2019] Available from: https://www.diabetes.org.uk/about_us/news/diabetes-prevalence-statistics International Diabetes Federation, IDF Diabetes Atlas Eight Edition 2017, Ch.5. [accessed 07 May 2019] Available from: http://diabetesatlas.org/IDF_Diabetes_Atlas_8e_interactive_EN/ Professor Aftab Ahmad. Foreword, 3. NHS North West Coast Strategic Clinical Network Diabetes Footcare Pathway Blueprint 2017.

$8 \quad$ NHS Diabetes Transformation Fund. [accessed 07 May 2019] Available from: https://www.england.nhs.uk/diabetes/diabetes-prevention/diabetes-transformation-fund

9 Ford M. Rise in amputations sparks call for key diabetes funding to continue. Nursing Times 17 Dec 2018 [accessed 07 May 2019] Available from: https://www.nursingtimes.net/news/primary-care/rise-in-amputations-sparks-call-for-keydiabetes-funding-to-continue/7027147.article

10 Buldt AK, Menz HB. Incorrectly fitted footwear, foot pain and foot disorders: A systematic search and narrative review of the literature. Journal of Foot and Ankle Research 2018; 11 : 43. https://doi.org/10.1186/s13047-018-0284-z.

11 Chantelau E, Gede A. Foot dimensions of elderly people with and without diabetes mellitus: A data basis for shoe design. Gerontology 2002; 48: 241-4. https://doi.org/10.1159/000058357.

12 McInnes AD, Hasmi F, Farndon LJ, Church A, Haley M, Sanger DM, Vernon W. Comparison of shoe-length fit between people with and without diabetic peripheral neuropathy: A casecontrol study. Journal of Foot and Ankle Research 2012; 5: 9-17. https://doi.org/10.1186/1757-1146-5-9.

13 Harrison SJ, Cochrane L, Abboud, RJ, Leese GP. Do patients with diabetes wear shoes of the correct size. Int J Clin Pract 2007; 61: 1900-1904. https://doi.org/10.1111/j.1742-1241.2007.01554.x

14 Reddy PV, Vaid MA, Child DF. Diabetes and incorrectly fitting shoes. Practical Diabetes 1989; 6: 16. https://doi.org/10.1002/pdi.1960060109.

15 Reiber GE. Who is at risk of limb loss and what to do about it? Journal of Rehabilitation Research and Development 1994; 31: 357-62. 

individuals with a history of diabetic foot ulcer: An emerging predictive marker for foot ulceration. Diabetes Care 2017; 40: e14-e15. https://doi.org/10.2337/dc16-2204. Fernando M, Crowther RG, Cunningham M, Lazzarini PA, Sangla KS, Buttner P et al. The reproducibility of acquiring three dimensional gait and plantar pressure data using established protocols in participants with and without type 2 diabetes and foot ulcers. Journal of Foot and Ankle Research 2016; 9: 4. https://doi.org/10.1186/s13047-016-0135-8. Kase R, Amemiya A, Okonogi R, Yamakawa H, Sugawara H, Tanaka YL et al. Examination of the effect of suitable size of shoes under the second metatarsal head and width of shoes under the fifth metatarsal head for the prevention of callus formation in health young women. Sensors 2018; 18: 3269. https://doi.org/10.3390/s18103269.

19 Tovaruela Carrión N, Becerro de Bengoa-Vallejo R, Losa Iglesias ME, Palomo-López P, Munuera-Martinez PV, Pérez-Garcia S et al. Accurately determining proper shoe size in patients with rheumatoid arthritis. Rehabilitation Nursing 2018; 43: 285-89. https://doi.org/10.1097/rnj.0000000000000040. Armstrong, DG, Lavery, LA, Harkless, LB. Validation of a diabetic wound classification system: The contribution of depth, infection, and ischemia to risk of amputation. Diabetes Care, 1998; 21: 855-59.

21 Tudhope L. The diabetic foot: Recognition and principles of management. Continuing Medical Education 2009; 27: 312-15.

22 Paiva de Castro A. The relationship between wearing incorrectly sized shoes and foot dimensions, foot pain, and diabetes. Journal of Sport Rehabilitation 2010; 19: 214-25, 216. ISO 7250-1: 2017 [accessed 07 May 2019] Available from: https://www.iso.org/standard/65246.html

24 Nancarrow S. The footwear suitability scale: A measure of shoe fit for people with diabetes. AJPM 1999; 33: 57-62.

25 Litzelman DK, Marriott DJ, Vinicor F. The role of footwear in the prevention of foot lesions in patients with NIDDM. Diabetes Care 1997; 20: 156-62.

26 Grau S, Barisch-Fritz B. Improvement of safety shoe fit - evaluation of dynamic foot structure. Footwear Science 2018; https://doi.org/10.1080/19424280.2018.1529062.

27 Van Netten JJ, Lazzarini PA, Armstrong DG et al. Diabetic foot Australia guidelines on footwear for people with diabetes. Journal of Foot and Ankle Research 2018; 11: 2-16. https://doi.org/10.1186/s13047-017-0244-z.

28 Canadian Association of Wound Care, Finding the Proper Shoe Fit, 3. [accessed 07 May 2019] Available from: https://guidelines.diabetes.ca/docs/patient-resources/finding-the-propershoe-fit.pdf

29 Tsung BYS, Zhang M, Ming Z, Fan YB, Boone, DA. Quantitative comparison of plantar foot shapes under different weight-bearing conditions. Journal of Rehabilitation Research and Development 2003; 40: 517-26.

30 Connolly JE, Wrobel JS. Recognizing the prevalence of changing adult foot size - an opportunity to prevent diabetic foot ulcers? Journal of the American Podiatric Medical Association 2014; 104: 118.

31 Belvedere C, Siegler S, Fortunato A, Caravaggi P, Liverani E, Durante S et al. New comprehensive procedure for custom-made total ankle replacements: Medical imaging, joint modeling, prosthesis design and 3D printing. J Orthop Res 2018. https://onlinelibrary.wiley.com/doi/full/10.1002/jor.24198 Telfer S, Woodburn J, Collier A, Cavanagh PR. Virtually optimized insoles for offloading the 
diabetic foot: A randomized crossover study. J Biomech 2017; 60: 157-61. https://doi.org/10.1016/j.jbiomech.2017.06.028.

Telfer S, Woodburn J. The use of 3D surface scanning for the measurement and assessment of the human foot. Journal of Foot and Ankle Research 2010; 3: 19-28. https://doi.org/10.1186/1757-1146-3-19. Lee $\mathrm{Y}$, Lin G, Wang MJ. Comparing 3D foot scanning with conventional measurement methods. Journal of Foot and Ankle Research 2014; 7:44-54. https://doi.org/10.1186/s13047-014-0044-7. Menz HB, Auhl M, Ristevski R, Frescos N, Munteanu SE. Evaluation of the accuracy of shoe fitting in older people using three-dimensional foot scanning. Journal of Foot and Ankle Research 2014; 7:3-13. https://doi.org/10.1186/1757-1146-7-3. Fairley $\mathrm{M}$. The pros and cons of computerized foot orthotic technology. November The O\&P Edge (2004). [accessed 07 May 2019] Available from: https://opedge.com/Articles/ViewArticle/2004-11_01

37 Dombroski CE, Balsdon ME, Froats A. The use of a low cost 3D scanning and printing tool in the manufacture of custom-made foot orthoses: A preliminary study. BMC Research Notes 2014; 7: 443-46. https://doi.org/10.1186/1756-0500-7-443.

38 Caravaggi P, Giangrande A, Lullini G, Padula G, Berti L, Leardini A. In shoe pressure measurements during different motor tasks while wearing safety shoes: The effect of custom made insoles vs. prefabricated and off-the-shelf. Gait Posture 2016; 50: 232-38. https://doi.org/10.1016/j.gaitpost.2016.09.013.

39 Stankovic K, Booth BG, Danckaers F, Burg F, Vermaelen P, Duerinck S et al. ThreeDimensional Quantitative Analysis of Health Foot Shape: A proof of concept study. Journal of Foot and Ankle Research 2018; 11: 8-21. https://dx.doi.org/10.1186\%2Fs13047-018-0251-8. Coudert T, Vacher P, Smits C, Van der Zande M. A method to obtain 3D foot shape deformation during the gait cycle. 9th International Symposium on the 3D Analysis of Human Movement: 28-30th June 2006 Valenciennes, France (2014).

41 Jezersek M, Mozina J. High-speed measurement of foot shape based on multiple-laserplane triangulation. Optical Engineering 2009; 48: 113604. [Cited 2019 Mar 19] Available from: https://www.spiedigitallibrary.org/journals/Optical-Engineering/volume-48/issue11/113604/High-speed-measurement-of-foot-shape-based-on-multiplelaser/10.1117/1.3265522.short?SSO=1

42 Kimura M, Mochimaru M, Kanade T. 3D measurement of feature cross-sections of foot while walking. Machine Vision and Applications 2011; 22: 377-88.

43 Barisch-Fritz B, Schmeltzpfenning T, Plank C, Grau S. Foot deformation during walking: Differences between static and dynamic 3D foot morphology in developing feet. Ergonomics 2014; 57: 921-33.

44 Rao S, Saltzman C and Yack HJ. Segmental foot mobility in individuals with and without diabetes and neuropathy. Clinical Biomechanics 2007; 22: 464-71. https://doi.org/10.1016/j.clinbiomech.2006.11.013.

45 Cheung JTM, Yu J, Wong DWC, Zhang M. Current methods in computer-aided engineering for footwear design. Footwear Science 2009; 1: 31-46. McCue TJ, When your foot hits the ground HP wants to customize the experience. Forbes Jan 29 2019. Niru K. ECCO launches mass production of 3D shoes. 3Dnatives Mar 26 (2018). [accessed 07 May 2019] Available from: https://www.3dnatives.com/en/ecco-launches-3d-shoes-260320184/

46 Leardini A, Benedetti MG, Berti L, Bettinelli D, Nativo R, Giannini S. Rear-Foot, Mid-Foot and Fore-Foot Motion During the stance phase of gait. Gait and Posture 2007; 25: 453-62. https://doi.org/10.1016/j.gaitpost.2006.05.017. 
47 Takabayashi T, Edama M, Yokoyama E, Kanaya C, Kubo M. Quantifying coordination among the rearfoot, midfoot, and forefoot segments during running. Sports Biomechanics 2018; 17: 18-32. https://doi.org/10.1080/14763141.2016.1271447.

48 Cheng YL, Hong Y. Using size and pressure measurement to quantify fit of running shoes. Footwear Science 2010; 2: 149-58.

49 Witana CP, Goonetilleke RS, Au EY, Xiang S, Lu X. Footbed shapes for enhanced footwear comfort. Ergonomics 2009; 52: 617-28. https://doi.org/10.1080/00140130802419503.

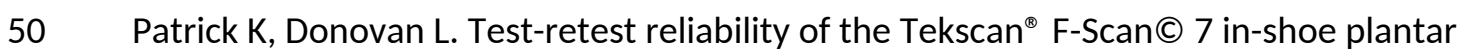
pressure system during treadmill walking in healthy recreationally active individuals. Sports Biomechanics 2018; 17: 83-97. https://doi.org/10.1080/14763141.2017.1355010.

51 Chen TL, Wong DW, Wang Y, Lin J, Zhang M. Foot arch deformation and plantar fascia loading during running with rearfoot strike and forefoot strike: A dynamic finite element Analysis. J Biomech 2019; 83: 260-72. https://doi.org/10.1016/j.jbiomech.2018.12.007.

52 Chen WP, Tang FT and Ju CW. Stress distribution of the foot during mid-stance to push-off in barefoot gait: A 3D finite element analysis. Clinical Biomechanics 2001; 16: 614-20.

53 Spirka TA, Erdemir A, Ewers Spaulding S, Yamane A, Telfer S, Cavanagh PR. Simple finite element models for use in the design of therapeutic footwear. Journal of Biomechanics 2014; 47: 2948-55. https://doi.org/10.1016/j.jbiomech.2014.07.020.

54 Chatzistergos PE, Naemi R, Chockalingam N. A method for subject-specific modelling and optimisation of the cushioning properties of insole materials used in diabetic footwear. Medical Engineering and Physics 2015; 37: 531-38. https://doi.org/10.1016/j.medengphy.2015.03.009.

55 Frykberg RG. Epidemiology of the diabetic foot: Ulcerations and amputations. Advances in Skin and Wound Care, 1999; 12: 139.

56 Kerr M. Improving foot care for people with diabetes and saving money: An economic study in England 2017. [accessed 07 May 2019] Available from: https://diabetes-resourcesproduction.s3-eu-west-1.amazonaws.com/diabetesstorage/migration/pdf/Improving\%2520footcare\%2520economic\%2520study\%2520\%28Jan uary\%25202017\%29.pdf

\section{Authors' Contribution Statement}

PJ and DW wrote the original article. RJB, MJD, KK, MM, DTPF have all read, amended and suggested changes relating to multiple draft versions. DTPF with his specialist knowledge wrote the section entitled After Scanning. All authors have read and approved the final manuscript. 
Table 1 Acceptable Foot-to-Shoe Length Gaps

\begin{tabular}{|l|l|l|l|}
\hline $\begin{array}{l}\text { Gap Range } \\
\text { (MM) }\end{array}$ & $\begin{array}{l}\text { Measurement } \\
\text { Method }\end{array}$ & Methodology & Paper \\
\hline $\begin{array}{l}<2 \mathrm{~mm} \\
\text { below shoe } \\
\text { size or } \\
\geq 10 \mathrm{~mm}\end{array}$ & Caliper & $\begin{array}{l}\text { From most prominent point in } \\
\text { calcaneal tuberosity region to tip of } \\
\text { longest toe (via longitudinal axis of } \\
\text { foot) }\end{array}$ & Paiva de Castro et al [22] \\
\hline 6-11mm & $\begin{array}{l}\text { Validated } \\
\text { Brannock } \\
\text { Device }\end{array}$ & $\begin{array}{l}\text { From back of heel cup to the end of } \\
\text { the longest toe }\end{array}$ & Tovaruela-Carrión [19] \\
\hline $\begin{array}{l}\text { 10-15mm } \\
\text { (similar to } \\
\text { Brannock) }\end{array}$ & $\begin{array}{l}\text { From tip of big toe to heel (sagittal } \\
\text { axis) }\end{array}$ & $\begin{array}{l}\text { Chantelau and Gede [11] } \\
\text { Mclnnes et al. [12] }\end{array}$ \\
\hline $\begin{array}{l}10 \mathrm{~mm} \\
\text { approx. }\end{array}$ & Not known & $\begin{array}{l}\text { Between end of toes and end of shoe } \\
\text { on weight-bearing (our emphasis) }\end{array}$ & Nancarrow [24] \\
\hline $\begin{array}{l}12.7- \\
15.9 \mathrm{~mm}\end{array}$ & $\begin{array}{l}\text { Manual } \\
\text { measurement }\end{array}$ & Manual assessment by nurse & $\begin{array}{l}\text { Litzelman Marriott and } \\
\text { Vinicor [25] }\end{array}$ \\
\hline $\begin{array}{l}\text { 10-20mm } \\
\text { Not known }\end{array}$ & $\begin{array}{l}\text { Foot length as measured from heel to } \\
\text { longest part of toe while standing }\end{array}$ & $\begin{array}{l}\text { Diabetic Foot Australia } \\
\text { Guideline on Footwear } \\
\text { [27] }\end{array}$ \\
\hline $\begin{array}{l}\text { Within 0.7 } \\
\text { magnitude } \\
\text { difference }\end{array}$ & Clarks Device & $\begin{array}{l}\text { Seated measurement, no definition of } \\
\text { length' }\end{array}$ & Harrison et al. [13] \\
\hline \begin{tabular}{l} 
Unspecified \\
\hline
\end{tabular} & Not known & $\begin{array}{l}\text { Standing measurement, no definition } \\
\text { of fit length }\end{array}$ & Kase et al. [18] \\
\hline
\end{tabular}


Table 2: Acceptable Foot-to-Shoe Width Gaps

\begin{tabular}{|l|l|l|l|}
\hline $\begin{array}{l}\text { Gap Range } \\
\text { (MM) }\end{array}$ & $\begin{array}{l}\text { Measurement } \\
\text { Method }\end{array}$ & Methodology & Paper \\
\hline $\begin{array}{l}\text { Foot width }= \\
\text { shoe width } \\
\text { +/- incorrect }\end{array}$ & $\begin{array}{l}\text { Validated } \\
\text { Brannock } \\
\text { Device }\end{array}$ & Forefoot transversal line & Touvaruela-Carrión [19] \\
\hline $\begin{array}{l}\text { Not } \\
\text { specified }\end{array}$ & $\begin{array}{l}\text { WMS Device } \\
\text { (similar to } \\
\text { Brannock) }\end{array}$ & $\begin{array}{l}\text { Foot transversal diameter } \\
\text { (lateral to medial to the fifth } \\
\text { metatarsal head) }\end{array}$ & Chantelau and Gede [11] \\
\hline $\begin{array}{l}\text { Within 0.7 } \\
\text { magnitude } \\
\text { difference }\end{array}$ & Clarks Device & $\begin{array}{l}\text { Widest part of the foot, over the } \\
\text { metatarsal heads, whilst person was } \\
\text { standing }\end{array}$ & Harrison et al. [13] \\
\hline
\end{tabular}


Fig.1 Acceptable Foot-to-Shoe Length Gaps Visualisation

Gap Range (Shoe and Foot) in Millimetres (MM)

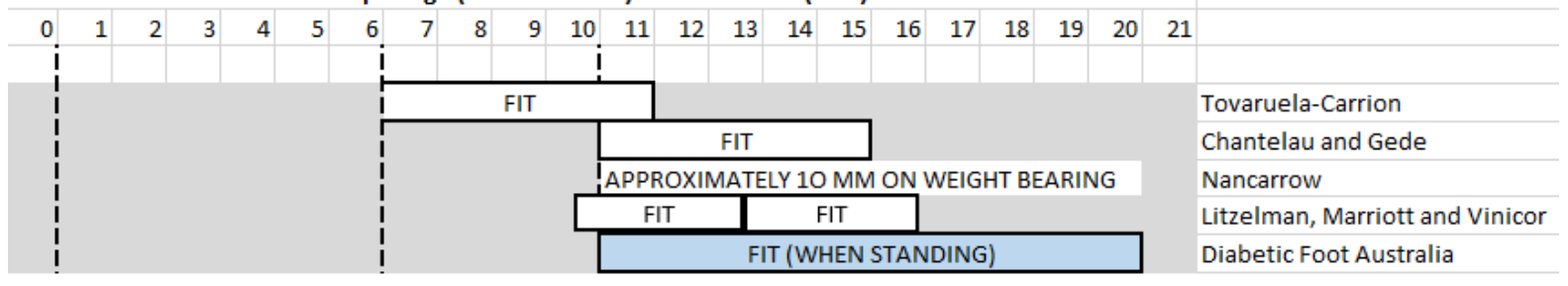

Litzelman, Marriott and Vinicor's study noted that the recommended extra length for shoes was originally given in inches as $1 / 2-5 / 8$ inches $(12.7 \mathrm{~mm}-15.87 \mathrm{~mm}$ ) although more recent studies suggested 3/8 - 1/2 inches $(9.5 \mathrm{~mm}-12.8 \mathrm{~mm}$ ). These two ranges were referred to. Tovaruela-Carrion also cite a modal gap of 9 $\mathrm{mm}$. 
Fig.2 3D Foot Morphology Measures (Illustration by P. Jones)

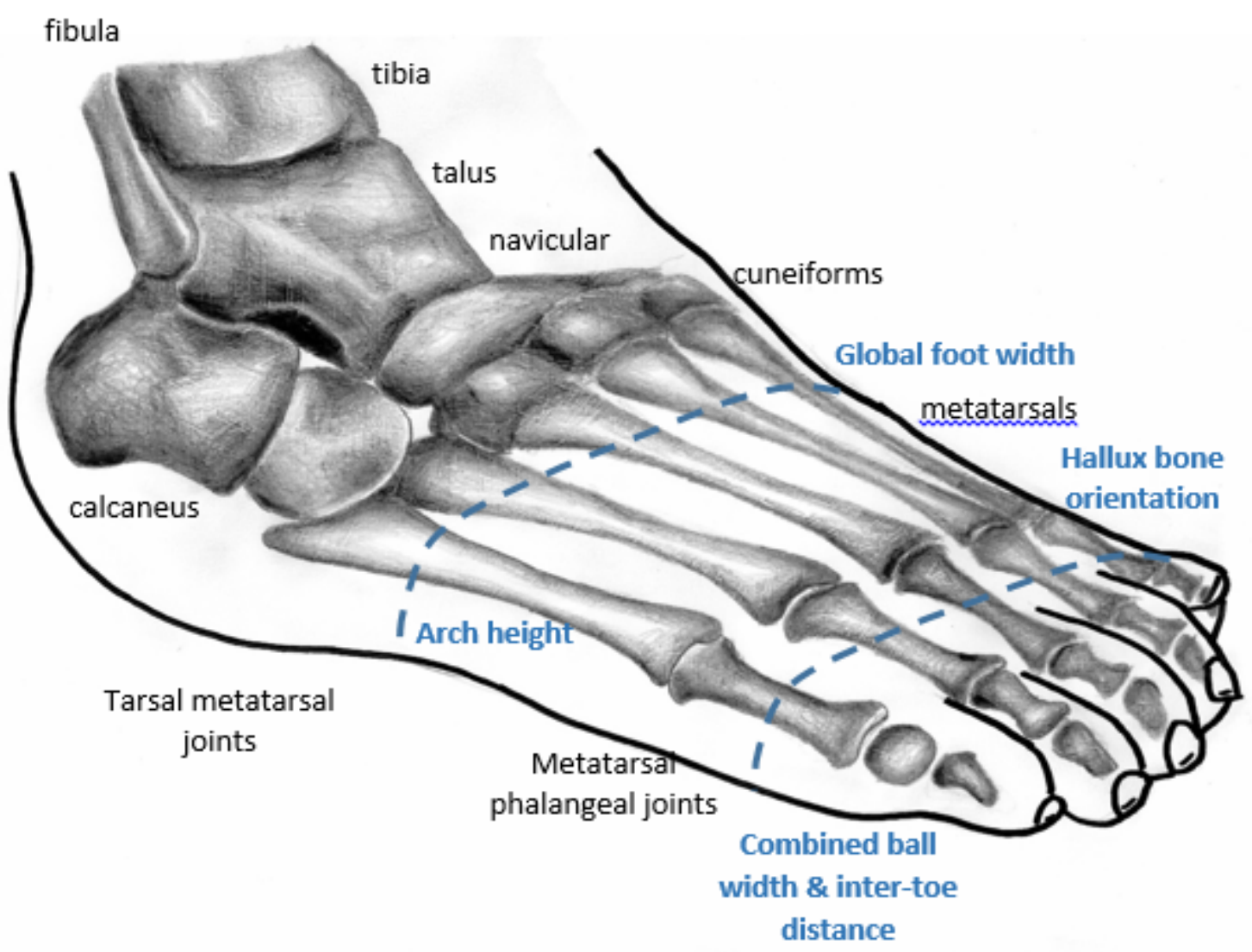


